\title{
Valuation of Guaranteed Maximum Price Contracts in Korea Using the Collar Option Model
}

\author{
Sanghyo Lee $\mathbb{D},{ }^{1}$ Hyeongjae Jang $\mathbb{D}^{2},{ }^{2}$ and Yonghan Ahn $\mathbb{D}^{2}$ \\ ${ }^{1}$ Division of Architecture and Civil Engineering, Kangwon National University, Samcheok 25913, Republic of Korea \\ ${ }^{2}$ Department of Architectural Engineering, Hanyang University, Ansan 15588, Republic of Korea \\ Correspondence should be addressed to Yonghan Ahn; yhahn@hanyang.ac.kr
}

Received 13 March 2018; Accepted 1 August 2018; Published 29 October 2018

Academic Editor: Dong Zhao

Copyright (c) 2018 Sanghyo Lee et al. This is an open access article distributed under the Creative Commons Attribution License, which permits unrestricted use, distribution, and reproduction in any medium, provided the original work is properly cited.

This study assessed the levels of risk that contractors may be subject to while executing a GMP contract by applying a collar option model to the case study of an apartment project in Korea and identified implications for the application of GMP contracts in Korea. The payoff structure of the GMP contract was defined based on the collar option model and a profit sharing ratio calculated to evaluate the risks involved in GMP contracts. The results showed that an increase in the GMP and a decrease in the expected cost and cost range were accompanied by a decrease in the profit sharing ratio. The proposed valuation model for GMP contracts is expected to help clients and contractors in Korea negotiate reasonable contracts as it enables the contractor to utilize the proposed model as basic data, the client to evaluate the performance of the contractor, and both parties to agree a reasonable profit sharing ratio. Implementing GMP contracts with CMR is likely to have a number of positive effects on the Korean construction market. However, in order to maximize these effects, it is necessary to have the ability to evaluate cost uncertainty. Accordingly, it is very important to analyze the factors that influence cost volatility. In future work, the various factors that have an impact on the GMP must be studied to maximize the positive effects of the framework proposed in this paper. An analysis of the effect of each factor on the change in the GMP will help Korean construction companies who are attempting to introduce GMP contracts to perform their preconstruction services effectively.

\section{Introduction}

In Korea, most public projects use the DBB project delivery system. However, according to a Ministry of Land, Infrastructure and Transport (MOLIT), such public projects often fail to identify all the construction risks during the design phase, leading to problems such as frequent design changes, cost overruns, time delays, and legal disputes. In addition, under the traditional fixed-price lump-sum contract, public projects have long suffered from limited trust among the contracting parties, lack of incentives, and misalignment of objectives, all of which tend to result in a confrontational working culture and lead to unfavorable project performance [1]. There is also a tendency to award contracts to the lowest bidders, which more often than not results in low profit margins, so consultants and contractors have little incentive to go beyond the minimum contractual requirements [2].

Korea's MOLIT is seeking to address the abovementioned problems by introducing a new approach, construction management at risk (CMR), into public projects. CMR emphasizes cooperation between the contracting parties, with the construction manager being in charge of the overall project execution and managing the design and construction contracts. Here, the construction manager is responsible for engaging in a designer consultation process that produces an optimal design that comprehensively considers both cost and schedule. In addition, the construction manager at risk must ensure that the entire construction process satisfies the owner's requirements 
concerning various aspects of the project, including the cost and schedule, while simultaneously staying within the guaranteed maximum price (GMP) [3-5].

In particular, a GMP contract is significant in terms of risk management, as this approach was originally introduced as an alternative integrated form of procurement to enable clients to minimize risk and integrate the diverse elements of a complex construction project [6]. GMP is a combination of a cost reimbursement contract and an option-like clause [7]. As an incentive-based procurement strategy, it rewards the contractor for any savings made against the GMP and penalizes him when this sum is exceeded because of his own mismanagement or negligence according to a preagreed share ratio [8]. This means that setting the GMP is a crucial step as the risk of cost overruns is entirely shouldered by the contractor. Particularly in Korea, where CMR is being introduced into public projects for the first time, identifying the predictable risk level of a contract is crucial for a reasonable GMP contract.

This study assessed the levels of risk that contractors may be subject to while executing a GMP contract by applying a collar option model to the case study of an apartment project in Korea and identified implications for the application of GMP contracts in Korea.

\section{Literature Review}

Design-Bid-Build (DBB), Design-Build (DB), and Construction Management at Risk (CMR) are the most general types of project delivery systems. Among these, DBB is the project delivery system traditionally used, with both DB and CMR being actively adopted as alternative systems designed to overcome the drawbacks of DBB. The increasing popularity of $\mathrm{DB}$ and CMR has encouraged the use of GMP contracts. Following this trend, several studies have conducted comprehensive examinations of the effects and/or practical implications of GMP contracts. Rojas et al. (2008) compared the cost growth performance of CMR and DBB in public school projects in the Pacific Northwest in the United States, finding that the school project costs exceeded the GMP in $75 \%$ of the cases they examined. This demonstrates the difficulties involved in determining a realistic GMP for such projects [9]. Bogus et al. analyzed contract payment provisions and project performance in the water and wastewater industry, reporting that implementing GMP yielded better performance in terms of both cost control and schedule growth [10].

Multiple participants collaborate in the planning/design process during the preconstruction phase, in the course of which the GMP is continuously reestimated. This means that an efficient cooperation system is crucial to minimize the difference between the GMP and the actual project cost. Several previous studies have emphasized the importance of effective partnerships between the contracting parties. For example, Bresnen and Marshall explored partnerships and related forms of collaboration in the UK construction industry and investigated the economic, organizational, and technical factors that encourage or inhibit collaboration between contracting partners [11]. Walker et al. clarified the nature of project alliances and discussed how alliance member organizations are selected [12]. Hauck et al. determined the extent to which the National Museum of Australia project was able to effectively incorporate the theoretical underpinnings of the collaborative process [13].

Since effective cooperation between the various parties of a GMP contract can increase the owner's profit, several studies have also examined an additional profit structure. Broome and Perry investigated how different sharing fractions are established for cost over- or underruns and how these fractions can vary depending on the degree of the cost over- or underruns compared with the target. They showed that utility theory alone is insufficient to deal with the complex interactions among the factors that govern the choice of the share profile [14]. Badenfelt sought to provide a broader understanding of target cost arrangements via an empirical study of the choice of sharing ratios from the perspective of both clients and contractors [15], while Rose and Manley provided a set of recommendations for construction clients who design and implement financial incentive mechanisms in projects [16]. Boukendour and Bah defined a GMP contract as a combination of a cost reimbursement contract and an option-like clause and examined how the option pricing model must be adapted in order to estimate the value of the GMP clause as a call option [7].

All the abovementioned studies examined the specific characteristics of a GMP contract and highlighted the importance of setting a reasonable GMP. A GMP contract represents a measure of risk management and provides insurance against the uncertainty of cost overruns for the client, while the contractor is responsible for the risk of cost overruns. Rojas et al. (2008) found that in reality, the construction cost often exceeds the GMP even in the US, where CMR is more actively implemented [9]. In Korea, where implementing CMR in public projects is in its infancy, it is very important to assess the level of risk transfer in a GMP contract and identity the related implications.

\section{Research Methodology}

This study utilized a collar option model to create a valuation capable of addressing the structural properties of a GMP contract appropriately. An option is a security giving the right to buy or sell an asset, subject to certain conditions, within a specified period of time [17]. An option is a right, but not an obligation, to take an action in the future. In financial markets, the most common types of options are a call option and a put option. A call option gives the owner the right to buy a stock at a predetermined exercise price on a specified maturity date. A put option can be viewed as the opposite of a call option. A put option gives its owner the right to sell the stock at a fixed exercise price. Stock prices are notorious for their volatility [18].

A collar option is a more complex arrangement as it effectively combines the call and put options [19]. A popular type of collar is the zero cost collar. Typically, the proceeds 
from the sale of the call are used to offset the cost of the put, which eliminates the cost of the hedging instrument. The put provides the holder with insurance to protect against any downward movement in the stock price below the exercise price. Any movement above the exercise price of the call represents lost profit [20].

In addition to clauses in the general service agreement between the owner and contractor, a GMP contract includes an optional clause related to cost variation. Here, either an incentive or a penalty is imposed on the contractor according to the construction cost based on the GMP. Incorporating such a payoff structure in a GMP contract can thus be conveniently explained by the collar option model.

\subsection{Framework for Valuing a GMP Contract Using a Collar} Option Model. The CMR process can be divided into the preconstruction phase and the construction phase. Figure 1 shows how in the preconstruction phase, the general contractor improves the accuracy of the initially determined GMP by providing various services. Hence, the initial GMP $\left(\mathrm{GMP}_{\mathrm{i}}\right)$ develops into the final GMP $\left(\mathrm{GMP}_{\text {fix }}\right)$ as a result of these preconstruction services. $\mathrm{GMP}_{\text {fix }}$ can vary according to the design quality and preconstruction services and may also differ from the final cost $\left(\operatorname{Cost}_{\mathrm{A}}\right)$ incurred in the actual construction phase as a result of cost uncertainty. Although $\mathrm{GMP}_{\mathrm{i}}$ has the greatest variability in terms of cost volatility, this variability is decreased by the performance of various preconstruction services designed to determine $\mathrm{GMP}_{\text {fix }}$ more accurately. If the preconstruction services are ineffective, the variability of GMP does not decrease, and thus $\alpha$ and $\beta$ in Figure 1 become equivalent. In this regard, $\mathrm{GMP}_{\mathrm{i}}$ may be considered as one case of $\mathrm{GMP}_{\text {fix }}$. On the contrary, if the preconstruction services are effective, the difference between $\alpha$ and $\beta$ will increase. In addition, the uncertainty during the construction phase is considered in the variation section of $\mathrm{GMP}_{\text {fix }}$, which includes Cost $_{\mathrm{A}}$.

Since Korea is only in the initial stages of introducing CMR and thus lacks extensive experience in its implementation, the data needed to establish realistic risk valuations for GMP contracts have not yet been sufficiently established. This paper attempts to overcome this lack of basic data by assuming that DBB is the worst case of a CMR delivery system, where the preconstruction services are minimal at best. As better preconstruction services are applied, the cost uncertainty improves, and GMP is reestimated. Thus, if a change in the value of the GMP contract due to some variation in the variables can be identified, the risk transfer level of the GMP contract can be assessed more effectively.

A GMP contract has an unusual payoff structure as it includes not only construction costs but also a contingency fund and the contractor's fee. Figure 2 shows how the payoff structure of a GMP contract is configured. In reality, a contractor loss does not always occur when the actual cost exceeds the expected cost incorporated in the GMP: only when the actual cost exceeds, not only the expected cost but also the contingency and contract fee included in the GMP does the contractor suffer a loss. On the contrary, if the actual cost comes in considerably lower than the expected cost, a clause is included that specifies how any such profit is to be shared.

In this respect, the payoff structure of a GMP contract based on cost variation can be schematically represented using the collar option model, as shown in Figure 3 As is clear from the figure, the underlying asset is defined as the cost. The collar option model basically comprises a section allowing the owner to exercise their call option owing to cost increases (Section A), a section for exercising the contractor's put option owing to a cost decrease (Section B), and a neutral section (Section $\mathrm{C}$ ).

Here, the exercise price $\left(X_{c}\right)$ of the call option is defined as GMP. As noted above, GMP actually includes not only an expected cost estimated at the time of signing the contract but also the contingency fund and the contractor's profit margin. Accordingly, even if the actual cost exceeds the expected cost, the contractor's loss does not immediately occur but is covered by the contingency and profit margin. In other words, since the GMP corresponds to the point where any increase in the cost generates a loss for the contractor, the exercise price $\left(X_{c}\right)$ of the call option is the GMP.

The exercise price $\left(X_{\mathrm{p}}\right)$ of a put option is defined as the expected cost. Hence, when the actual cost is below the expected cost, this cost saving immediately generates a profit. Therefore, it is reasonable to set the exercise price $\left(X_{\mathrm{p}}\right)$ of the put option to be the expected cost. As the underlying asset $\left(S_{\mathrm{o}}\right)$ is the cost estimated at the time of signing the GMP contract, it is defined as the expected cost. Consequently, the exercise price $\left(X_{\mathrm{p}}\right)$ of the put option is conceptually the same as the price of the underlying asset $\left(S_{\mathrm{o}}\right)$.

Overall, as shown in Figure 3, the owner secures a call option where GMP is the exercise price $\left(X_{c}\right)$, while the contractor secures a put option where the expected cost is the exercise price $\left(X_{\mathrm{p}}\right)$. It is reasonable for the GMP contract to place the same value on the optional clauses for the guarantee and profit options. When the GMP and expected cost are determined by agreement between the owner and contractor, the value of the guarantee held by the owner is determined. Consequently, if the value of the profit option in Section B, estimated from Equation (1) below, is adjusted by the profit sharing ratio $(\mathrm{K})$, which corresponds to the slope, the value of the guarantee secured by the owner and the incentive value of the contractor can be calculated identically. A relative increase in $K$ effectively indicates that the value of the guarantee obtained by the owner occupies a high proportion of the value of the profit option. As this signifies a relative increase in the effect of the guarantee, it can be inferred that the owner transfers more risk to the contractor.

$$
\begin{aligned}
\text { Value }_{\text {guarantee }} & =\text { Value }_{\text {profit option }} \times K, \\
\text { Value }_{\text {profit option }}: \text { value of profit option, } & \\
\text { Value }_{\text {guarantee }}: \text { value of guarantee, } & \text { K: Profit sharing ratio. }
\end{aligned}
$$




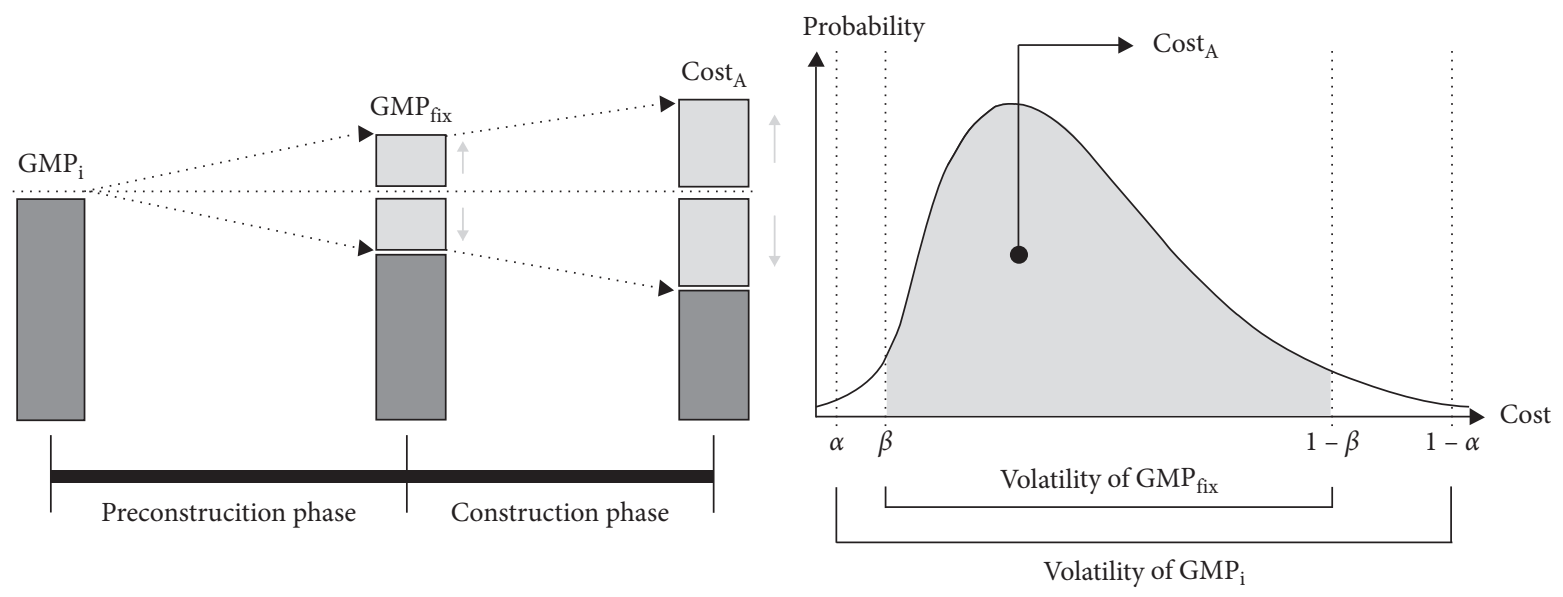

FIgURE 1: Uncertainty of $\operatorname{Cost}_{\mathrm{A}}$ (actual cost) in the GMP contract.

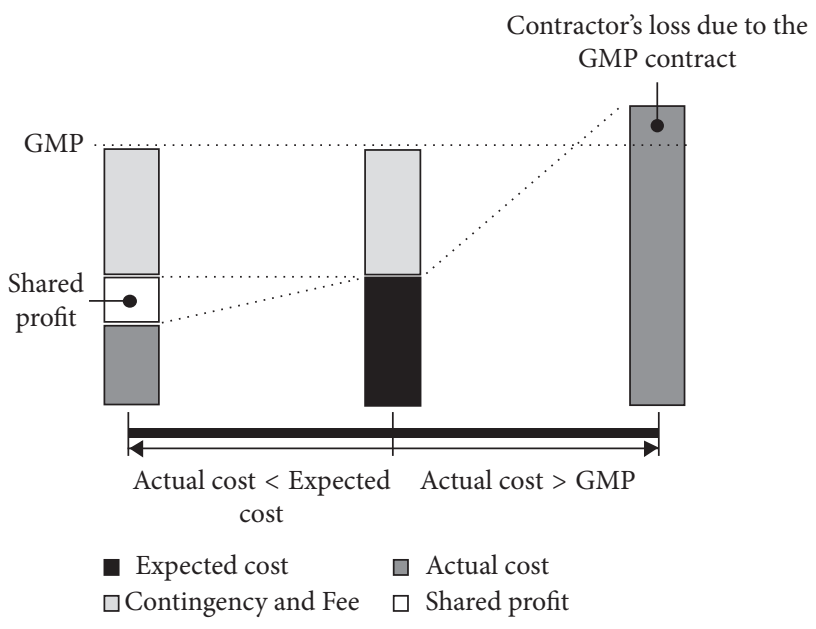

FIgUre 2: Payoff structure of the GMP contract.

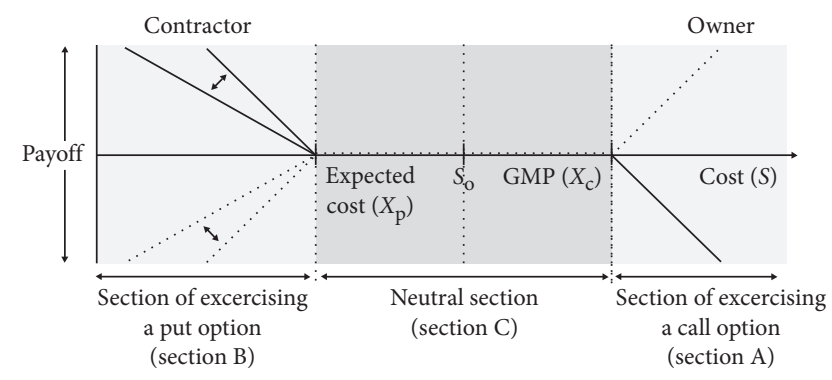

Figure 3: Valuation of the GMP contract based on the collar option model.

\subsection{Binomial Lattice Model for Calculating Option Value.} Cox et al. proposed the use of a binomial lattice model to calculate option values under the assumption that any change in the underlying asset will have a binomial distribution. The binomial lattice model can solve complex and realistic option pricing problems [21]. The model consists of two processes: one is the forward process, where the binomial tree of the distribution of the underlying asset is configured as shown in Figure 4, the other is the backward process, where the binomial tree for calculating the option value is configured as shown in Figure 5 [22].

In the first step, the underlying asset $(S)$ must be determined in the binominal tree. As shown in Figure 3, the value of the GMP contract varies according to changes in the cost. Accordingly, the present value of the expected cost of a project is defined as the underlying asset $(S)$. The binomial tree formed by the forward process can be considered a process in which the cost may change over time owing to uncertainty. In this regard, the binomial tree in Figure 4 repeatedly calculates the rise rates $(u)$ and the fall rates $(d)$ of the underlying asset $(S)$, both of which depend on the volatility of the underlying asset. However, if the maximum and minimum values of the underlying asset $(S)$ can be identified at the final point, the probabilities can be calculated by the following Equations [23].

$$
\begin{gathered}
u=\sqrt[t]{\frac{S_{u^{t}}}{S_{\mathrm{o}}}}, \\
d=\sqrt[t]{\frac{S_{d^{t}}}{S_{\mathrm{o}}}}
\end{gathered}
$$

where $t=$ construction period, $S_{u^{t}}=$ maximum expected cost at the final point $(t)$, and $S_{d^{t}}=$ minimum expected cost at the final point $(t)$.

Based on the binomial tree completed by the forward process, the backward process calculates the option value. The binomial tree in Figure 5 presents the iterative calculation process where the option value of each node is obtained by the equation of the final point, and then Equation (4) is used to calculate the value of the present node. At the same time, the risk-neutral probabilities $(p)$ are obtained from Equation (5). In summary, the binomial lattice model is used here to calculate the values of the guarantee and incentives and then the profit sharing ratio determined by applying Equation (1). 


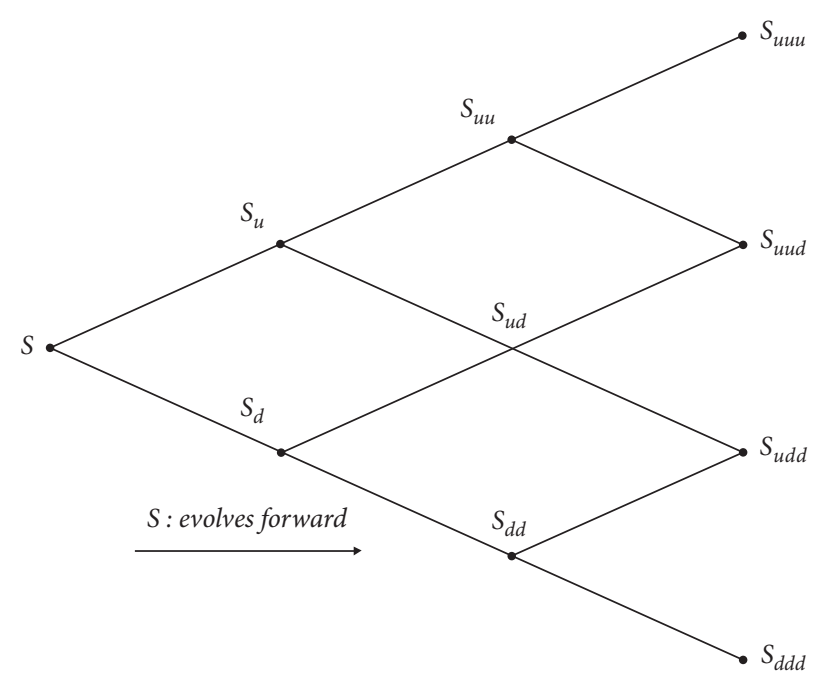

FIGURE 4: Binomial tree for the underlying asset distribution (forward process).

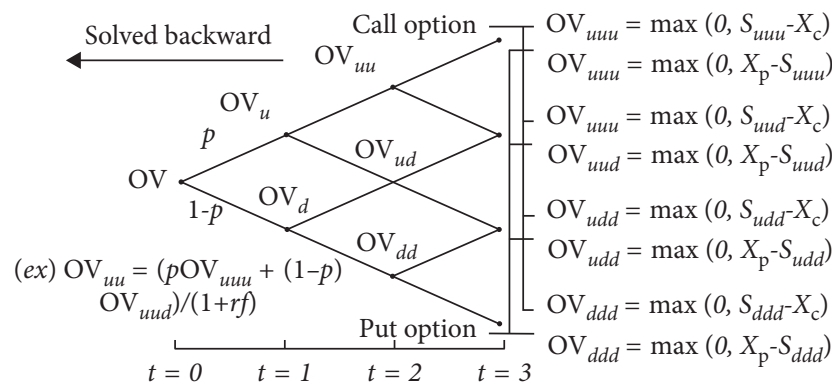

FIgURE 5: Binomial tree for solving the option value (backward process).

$$
\begin{aligned}
\mathrm{OV}_{u u} & =\frac{p \mathrm{OV}_{u u u}+(1-p) \mathrm{OV}_{u u d}}{1+r f_{\text {month }}}, \\
r f & =p \times(u-1)+(1-p) \times(d-1),
\end{aligned}
$$

where $r f=$ risk-free rate, $p=$ risk-neutral probabilities, $u=$ rise rates, and $d=$ fall rates.

3.3. Approach for Setting the Maximum and Minimum Expected Costs. As noted earlier, the maximum and minimum values of the expected cost are needed to calculate the rise $(u)$ and fall $(d)$ rates of the binomial tree. To this end, 18,090 cases of cost changes from 331 apartment house projects, all in Korea, were utilized. The basic information of sample projects is as shown in Table 1 below.

As shown by the sample projects in Table 2, the cost reduction represented only $14.2 \%$ of the total, with the great majority, $85.5 \%$, experiencing cost increases, which indicates a very high likelihood of cost overruns. However, in both cases, a very high proportion (72.5\%) of the cost variation ratios was within $5 \%$, with only $6.9 \%$ exceeding $20 \%$.
TABLE 1: Basic information of sample projects.

\begin{tabular}{lcc}
\hline Category & Classification & Project number (\%) \\
\hline \multirow{2}{*}{ Owner type } & Public & $331(100.0)$ \\
& Private & $0(0.0)$ \\
\hline \multirow{2}{*}{ Project type } & Residential & $331(100.0)$ \\
& Nonresidential & $0(0.0)$ \\
\hline & $\sim 50,000$ & $132(39.88)$ \\
G.F.A $\left(\mathrm{m}^{2}\right)$ & $50,000 \sim 100,000$ & $158(47.73)$ \\
& $100,000 \sim 150,000$ & $30(9.06)$ \\
& $150,000 \sim 200,000$ & $10(3.02)$ \\
& $200,000 \sim$ & $1(0.30)$ \\
\hline \multirow{3}{*}{ Project period (month) } & $\sim 20$ & $31(9.37)$ \\
& $20 \sim 30$ & $273(82.48)$ \\
& $30 \sim 40$ & $25(7.55)$ \\
& $40 \sim$ & $2(0.60)$ \\
\hline
\end{tabular}

Based on the cost variation data for the sample projects, the frequency and severity distributions were derived. Frequency indicates the number of occurrences of cost change, and severity is defined as the cost variation ratio when cost changes occur. The expected cost distribution was determined by a Monte Carlo simulation using the frequency and severity distributions. Finally, the maximum and minimum expected costs were calculated based on the expected cost distribution.

\subsection{Case Study of Valuing a GMP Contract Based on the Collar} Option Model. An apartment house project that employed $\mathrm{DBB}$ was used for the case study presented here to assess the real-world performance of a GMP contract in Korea. As noted above, DBB is assumed to be the worst case, where the preconstruction service of the CMR delivery system is minimally applied, and the uncertainty of the construction cost is at its greatest.

As shown in Table 3, the apartment house project had a gross floor area of $51,861 \mathrm{~m}^{2}$ and lasted for 2 years. The expected cost of the project was $\$ 47,756,721$, and the GMP was set to $\$ 51,157,000$ to reflect the contingency and contract fee. Table 2 provides an overview of the project. The process rate is $43 \%$ at the first year and $57 \%$ at the second year.

Table 4 presents the main factors used to evaluate the option value inherent in the GMP contract for the apartment house project. The expiration period of the case was 2 years, which corresponds to the construction period, and the time step was calculated to be 1 year. The risk-free rate was set at $2.349 \%$, which was the average interest rate of 5-year public bonds at the time the project commenced. The underlying asset served as the starting point for calculating various estimates of the construction cost and reflected the volatility related to uncertainty. The present value of the underlying asset was then calculated by distributing the expected cost at the time of signing the contract across each time period in accordance with the process rate and applying a discount rate. The discount rate was calculated by adding the average annual inflation rate $(1.300 \%)$ for the previous 5 years and the above risk-free rate $(2.349 \%)$. Consequently, the underlying asset (S) was determined to be $\$ 45,150,831$. 
TABLE 2: Cost variation ratios of sample projects.

\begin{tabular}{lcccc}
\hline Cost variation ratio (\%) & \multicolumn{2}{c}{$\begin{array}{c}\text { Project number } \\
(\%)\end{array}$} & Average contract amount (\$ thousand) & Average final amount (\$ thousand) \\
\hline Total & 331 & $(100.0)$ & 33,348 & 37,726 \\
$-5-0$ & 47 & $(14.2)$ & 32,233 & 32,040 \\
$0-5$ & 193 & $(58.3)$ & 30,123 & 30,749 \\
$5-10$ & 42 & $(12.7)$ & 42,106 & 45,263 \\
$10-15$ & 26 & $(7.9)$ & 41,303 & 46,974 \\
$15-20$ & 16 & $(4.8)$ & 38,854 & 46,906 \\
$20-25$ & 7 & $(2.1)$ & 36,687 & 46,848 \\
\hline
\end{tabular}

TABle 3: Project overview.

\begin{tabular}{lcc}
\hline Category & Item & Details \\
\hline & Construction period & 2 years \\
Basic information & Number of floors & A basement and a 20-floor building \\
& Number of households & 394 households (5 apartment blocks) \\
& Reinforced concrete & $51,861 \mathrm{~m}^{2}$ \\
\hline & Gross floor area & $\$ 47,756,721$ \\
GMP & Expected cost & $\$ 1,432,702$ \\
& Contingency & $\$ 1,967,577$ \\
Progress rate & Contract fee & $\$ 51,157,000$ \\
\hline
\end{tabular}

TABLE 4: Valuables used for calculating option value.

\begin{tabular}{lc}
\hline Variables & Estimated value \\
\hline Underlying asset $(S)$ & $\$ 45,150,831$ \\
Exercise price of call option $\left(X_{\mathrm{c}}\right)$ & $\$ 51,959,689$ \\
Exercise price of put option $\left(X_{\mathrm{p}}\right)$ & $\$ 48,506,057$ \\
$S_{\max }$ & $\$ 62,074,638$ \\
$S_{\min }$ & $\$ 42,934,102$ \\
Risk-free rate $\left(r_{\mathrm{f}}\right)$ & $2.349 \%$ \\
Time interval & 1 year \\
Rise rates $(u)$ & 1.1725 \\
Fall rates $(d)$ & 0.9751 \\
Risk-neutral probability $(p)$ & 0.2449 \\
\hline
\end{tabular}

The exercise price $\left(X_{c}\right)$ of the call option in Section A, where the owner gains the value of the guarantee, was calculated to be $\$ 51,959,689$, which was hence the future price for GMP. In addition, the exercise price $\left(X_{p}\right)$ of the put option in Section C, where the value of the profit option is taken into account, was calculated to be $\$ 48,506,057$, which was the future price of the expected cost.

As explained earlier, the maximum and minimum values of the underlying asset (S) must be calculated to determine the rise and fall rates. Therefore, multiple cost change data were utilized to implement the Monte Carlo simulation, which resulted in the distribution.

Based on the simulation results, Table 5 shows the maximum and minimum values of the cost according to the volatility ranges. As the analysis of this case assumes that the failure to apply preconstruction services in the CMR delivery system is the worst case, this has the greatest uncertainty. Accordingly, since the largest range of cost to be applied for valuing the GMP contract is $0.05-99.95 \%$, the maximum and
TABle 5: Maximum and minimum values of cost.

\begin{tabular}{lcc}
\hline Range & Maximum value & Minimum value \\
\hline $0.05-99.95 \%(0.1 \%)$ & $\$ 62,074,638$ & $\$ 42,934,102$ \\
$0.5-99.5(1 \%)$ & $\$ 57,901,101$ & $\$ 44,945,033$ \\
$2.5-97.5(5 \%)$ & $\$ 55,190,504$ & $\$ 46,359,045$ \\
$5-95(10 \%)$ & $\$ 54,070,058$ & $\$ 46,819,569$ \\
$7.5-92.5(15 \%)$ & $\$ 53,414,426$ & $\$ 47,110,991$ \\
\hline
\end{tabular}

minimum values of cost were calculated to be $\$ 62,074,638$ and $\$ 42,934,102$, respectively. These values were used to determine the rise rate, the fall rate, and the risk-neutral probability by applying Equations (2), (3), and (5), respectively.

The variables in Table 4 were employed in the forward process to obtain the various probable values of the underlying asset. Based on the basic binomial lattice model produced by the forward process, the backward process for the call option model was applied to calculate the value of the guarantee obtained by the owner, and the value of the guarantee was $\$ 579,289$. Next, the value of the profit option was calculated by applying the backward process for the put option model, and the value of the profit option was $\$ 3,032,565$. As the value of the guarantee obtained by the owner should be the same as the incentive that the contractor could potentially obtain, a sharing ratio for the distribution of the value of the entire profit option was then calculated. Thus, Equation (1) was used to obtain a profit sharing ratio of $19.1 \%$, as presented in Table 6 .

Table 7 shows the variation in the $K$-ratio according to the GMP, the expected cost, and thus the cost range, and analyzes the risk transfer level of the GMP contract. In 
TABLE 6: Profit sharing ratio.

\begin{tabular}{lc}
\hline Category & Estimated value \\
\hline Value of guarantee & $\$ 579,289$ \\
Value of profit option & $\$ 3,032,565$ \\
Profit sharing ratio & $19.1 \%$ \\
\hline
\end{tabular}

TABLE 7: Fluctuation of $K$-ratio under various conditions.

\begin{tabular}{lcccccc}
\hline \multirow{2}{*}{ GMP (million \$) } & Range (\%) & \multicolumn{6}{c}{ Expected cost (million $\$$ ) } \\
& & 50.0 & 50.5 & 51.0 & 51.5 & 52.0 \\
\hline \multirow{5}{*}{52.0} & $0.05-99.95$ & 0.391 & 0.460 & 0.524 & 0.566 & 0.609 \\
& $0.50-99.50$ & 0.295 & 0.354 & 0.403 & 0.455 & 0.512 \\
& $2.50-97.50$ & 0.173 & 0.216 & 0.265 & 0.321 & 0.388 \\
& $5.00-95.00$ & 0.104 & 0.138 & 0.177 & 0.226 & 0.289 \\
& $7.50-92.50$ & 0.055 & 0.075 & 0.101 & 0.135 & 0.183 \\
\hline \multirow{5}{*}{52.5} & $0.05-99.95$ & 0.369 & 0.434 & 0.496 & 0.535 & 0.575 \\
& $0.50-99.50$ & 0.265 & 0.319 & 0.363 & 0.410 & 0.461 \\
& $2.50-97.50$ & 0.136 & 0.170 & 0.208 & 0.252 & 0.305 \\
53.0 & $5.00-95.00$ & 0.062 & 0.082 & 0.105 & 0.134 & 0.172 \\
& $7.50-92.50$ & 0.008 & 0.011 & 0.015 & 0.020 & 0.028 \\
\hline \multirow{5}{*}{54.0} & $0.05-99.95$ & 0.348 & 0.409 & 0.467 & 0.504 & 0.542 \\
& $0.50-99.50$ & 0.236 & 0.284 & 0.322 & 0.364 & 0.410 \\
& $2.50-97.50$ & 0.099 & 0.124 & 0.151 & 0.183 & 0.222 \\
& $5.00-95.00$ & 0.020 & 0.026 & 0.034 & 0.043 & 0.055 \\
& $7.50-92.50$ & 0.000 & 0.000 & 0.000 & 0.000 & 0.000 \\
\hline \multirow{5}{*}{5.5} & $0.05-99.95$ & 0.326 & 0.384 & 0.438 & 0.472 & 0.509 \\
& $0.50-99.50$ & 0.206 & 0.248 & 0.282 & 0.319 & 0.359 \\
& $2.50-97.50$ & 0.062 & 0.077 & 0.095 & 0.115 & 0.139 \\
& $5.00-95.00$ & 0.000 & 0.000 & 0.000 & 0.000 & 0.000 \\
& $7.50-92.50$ & 0.000 & 0.000 & 0.000 & 0.000 & 0.000 \\
\hline & $0.05-99.95$ & 0.305 & 0.359 & 0.409 & 0.441 & 0.475 \\
& $0.50-99.50$ & 0.177 & 0.213 & 0.242 & 0.273 & 0.308 \\
& $2.50-97.50$ & 0.025 & 0.031 & 0.038 & 0.046 & 0.056 \\
& $5.00-95.00$ & 0.000 & 0.000 & 0.000 & 0.000 & 0.000 \\
& $7.50-92.50$ & 0.000 & 0.000 & 0.000 & 0.000 & 0.000 \\
\hline & & & & & &
\end{tabular}

addition, based on the results shown in Table 7, Figures 6 and 7 present the schematic graphs of the $K$-ratio with one variable fixed and the remaining variables changeable.

In Figure 6, the increase in the GMP is accompanied by a decrease in the $K$-ratio. The increase in the GMP with a fixed expected cost indicates an increase in either the contingency or contract fee. As this again indicates an increase in the buffer within which the contractor can react to cost overruns, the actual cost becomes less likely to exceed the GMP. Thus, when GMP increases, the $K$-ratio decreases. On the contrary, Figure 7 shows that an increase in the expected cost is accompanied by an increase in the $K$-ratio. The increase in the expected cost with a fixed GMP indicates a decrease in either the contingency or contract fee. Hence, as the actual cost becomes more likely to exceed the GMP, the $K$-ratio increases. Interestingly, a decrease in the cost range was accompanied by a decrease in the $K$-ratio. As the accuracy of cost estimation is high, a decrease in the cost range means that there must be a relative reduction in the actual cost uncertainty. Thus, when the cost range decreases, the $K$-ratio also decreases.

Table 7 has been constructed based on the proposed valuation model used for the GMP contract. In a Korean
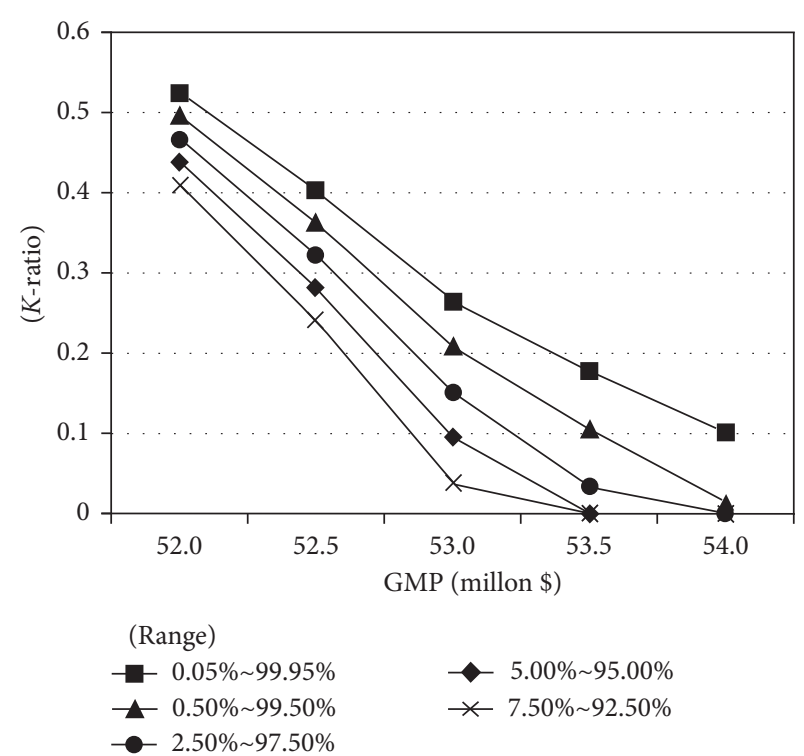

Figure 6: $K$-ratio at expected cost of $\$ 51$ (million).

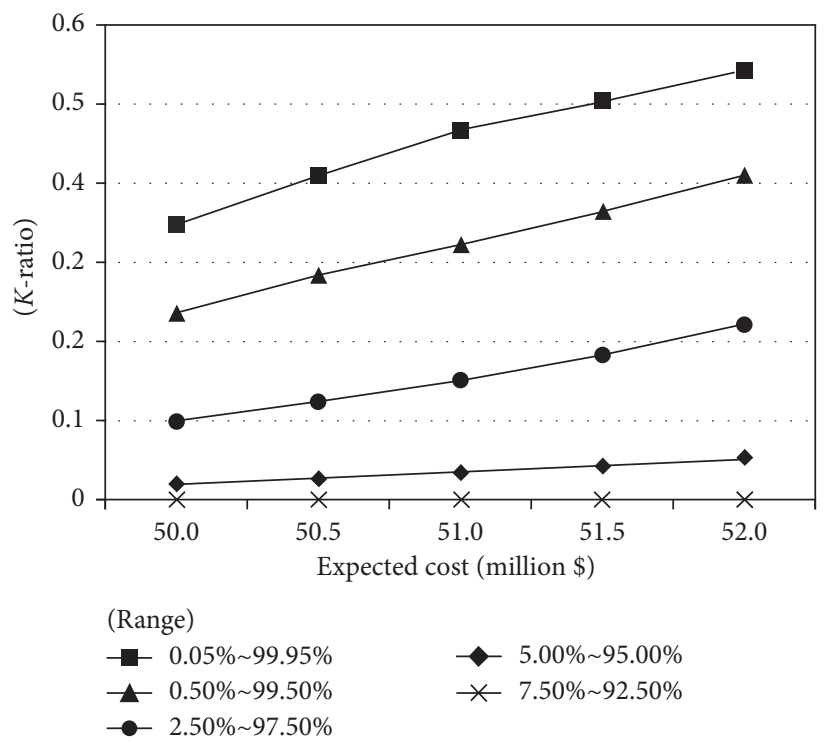

Figure 7: K-ratio at GMP of $\$ 53$ (million).

context, this table may help owners and contractors execute GMP contracts in a reasonable manner. If contractors continue to perform projects based on GMP contracts, they will be able to calculate the probability distribution of the accuracy when estimating the construction cost by using their own preconstruction services. Since such a probability distribution can ultimately be defined as the cost range, the valuation model used in this paper may help the contractor calculate a reasonable contingency fund and fee margin and thus determine the GMP. When making a GMP contract, the owner can utilize the proposed framework to determine a reasonable level of incentive according to the expected cost and GMP. A public ordering organization can accumulate performance data for the companies tendering for a project based on their track record from various projects and assess 
their performance using the data. Furthermore, as the accuracy of the GMP for each company is refined based on the valuation data, the organization will be able to effectively discuss the GMP or K-ratio with each tendering company in future projects.

\section{Discussion and Conclusion}

This study assessed the levels of risk that contractors may be subject to while executing a GMP contract by applying a collar option model to the case study of an apartment project in Korea and identified implications for the application of GMP contracts in Korea.

The framework proposed in this paper can be applied to evaluate a GMP contract, as it utilizes an established DBB project in the initial stage of CMR implementation. The framework can also apply the collar option model to analyze the unique payoff structure of a GMP contract and utilize the results of the analysis as an effective valuation tool. Finally, the framework can be utilized to set a reasonable profit sharing ratio and then apply this to assess the contractor's risk level. In other words, the valuation model allows owners and the general contractors to provide useful information in decision-making of GMP contract. Utilizing the analysis results, owners and general contractors can discuss reasonable GMP, profit sharing ratio. By confirming the risk transfer level based on the change of $K$-ratio, the contracting parties can effectively evaluate a reasonable contingency fund and fee margin.

The analysis results showed that an increase in the cost uncertainty is accompanied by an increase in the risk level of a GMP contract. This means that an increase in the cost range or GMP is ultimately related to cost uncertainty, indicating that the contractor's estimation ability is an important factor in assessing the risk level of a GMP contract. The preconstruction phase of CMR is vital for enhancing the accuracy of cost estimation. Thus, the contractor's estimation can be improved by implementing CMR. However, as the existing DBB method is currently widely used in Korea, stakeholders are not accustomed to participating in a collaborative process and thus may have considerable difficulty in communicating with other participants. Therefore, domestic contractors should seek to enhance their competency in preconstruction services by forming a partnership or joint venture with overseas consulting companies that have already implemented a systematic collaboration process.

Utilizing a GMP contract within a CMR application could highlight the importance of risk management in Korea. In the past, many Korean companies have tended to depend on sales strategies rather than business management strategies. However, the capability of a company can be directly related to the possibility of winning a GMP contract. In particular, estimation accuracy, which varies according to the capabilities of each company, is essential when setting the GMP. In this regard, a GMP contract will have positive effects on the development of the Korean construction industry.
In this paper, the proposed model is based on uncertainty of actual cost. Therefore, rather than validating the accuracy of the model by using the actual cost, this paper focused on presenting the reference that confirmed the risk transfer level based on the change of K-ratios. As can be confirmed from the analysis results, it is necessary to minimize the cost volatility for a successful GMP contract. Accordingly, it is very important to analyze the factors that influence cost volatility. In future work, the various factors that have an impact on the GMP must be studied to maximize the positive effects of the framework proposed in this paper. A comparative analysis of the effect of each factor on the change in the GMP will help Korean construction companies who are attempting to introduce GMP contracts to perform their preconstruction services effectively.

\section{Data Availability}

Data generated or analyzed during the study are available from the corresponding author upon request.

\section{Conflicts of Interest}

The authors declare that there are no conflicts of interest regarding the publication of this paper.

\section{Acknowledgments}

This research was supported by Basic Science Research Program through the National Research Foundation of Korea (NRF) funded by the Ministry of Science, ICT and Future Planning (No. 2015R1A5A1037548).

\section{References}

[1] D. Walker and K. Hampson, Procurement Strategies: A Relationship-Based Approach, Blackwell, Oxford, UK, 2003.

[2] D. Chan, A. Chan, P. Lam, E. Lam, and J. Wong, "Evaluating guaranteed maximum price and target cost contracting strategies in Hong Kong construction industry," Journal of Financial Management of Property and Construction, vol. 12, no. 3, pp. 139-149, 2007.

[3] V. E. Sanvido and M. Konchar, Selecting Project Delivery Systems: Comparing Design-Build, Design-Bid-Build and Construction Management at Risk, The Project Delivery Institute, State College, PA, USA, 1999.

[4] T. Warne and J. Beard, Project Delivery Systems Owner's Manual, American Council of Engineering Companies, Washington, DC, USA, 2005.

[5] I. M. Mahdi and K. Alreshaid, "Decision support system for selecting the proper project delivery method using analytical hierarchy process (AHP)," International Journal of Project Management, vol. 23, no. 7, pp. 564-572, 2005.

[6] D. Trench, On Target: A Design and Manage Target Cost Procurement System, Thomas Telford, London, UK, 1991.

[7] S. Boukendour and R. Bah, "The guaranteed maximum price contract as call option," Construction Management and Economics, vol. 19, no. 6, pp. 563-567, 2001.

[8] J. W. E. Masterman, An Introduction to Building Procurement Systems, Spon, London, UK, 2nd edition, 2002.

[9] E. Rojas and I. Kell, "Comparative analysis of project delivery systems cost performance in Pacific Northwest public 
schools," Journal of Construction Engineering and Management, vol. 134, no. 6, pp. 387-397, 2008.

[10] S. M. Bogus, J. S. Shane, and K. R. Molenaar, "Contract payment provisions and project performance: an analysis of municipal water and wastewater facilities," Public Works Management and Policy, vol. 15, no. 1, pp. 20-31, 2010.

[11] M. Bresnen and N. Marshall, "Building partnerships: case studies of client-contractor collaboration in the UK construction industry," Construction Management and Economics, vol. 18, no. 7, pp. 819-832, 2000.

[12] D. H. T. Walker, K. Hampson, and R. Peters, "Project alliancing vs project partnering: a case study of the Australian National Museum Project," Supply Chain Management: An International Journal, vol. 7, no. 2, pp. 83-91, 2002.

[13] A. J. Hauck, D. H. T. Walker, K. D. Hampson, and R. J. Peters, "Project alliancing at national Museum of Australiacollaborative process," Journal of Construction Engineering and Management, vol. 130, no. 1, pp. 143-152, 2004.

[14] J. Broome and J. Perry, "How practitioners set share fractions in target cost contracts," International Journal of Project Management, vol. 20, no. 1, pp. 59-66, 2002.

[15] U. Badenfelt, "The selection of sharing ratios in target cost contracts," Engineering, Construction and Architectural Management, vol. 15, no. 1, pp. 54-65, 2008.

[16] T. Rose and K. Manley, "Client recommendations for financial incentives on construction projects," Engineering, Construction and Architectural Management, vol. 17, no. 3, pp. 252-267, 2010.

[17] F. Black and M. Scholes, "The pricing of options and corporate liabilities," Journal of Political Economy, vol. 81, no. 3, pp. 637-659, 1973.

[18] J. C. Hull, Options, Futures, and Other Derivatives, PrenticeHall, NJ, USA, 1985.

[19] L. Shan, M. J. Garvin, and R. Kumar, "Collar options to manage revenue risks in real toll public-private partnership transportation projects," Construction Management and Economics, vol. 28, no. 10, pp. 1057-1069, 2010.

[20] J. C. Bettis, J. M. Bizjak, and M. L. Lemmon, "Managerial ownership, incentive contracting, and the use of zero-cost collars and equity swaps by corporate insiders," Journal of Financial and Quantitative Analysis, vol. 36, no. 3, pp. 345370, 2001.

[21] J. Cox, S. Ross, and M. Rubinstein, "Option pricing: a simplified approach," Journal of Financial Economics, vol. 7, no. 3, pp. 229-263, 1979.

[22] P. S. Ho and L. Y. Liu, "How to evaluate and invest in emerging A/E/C technologies under uncertainty," Journal of Construction Engineering and Management, vol. 129, no. 1, pp. 16-24, 2003.

[23] Q. Cui, P. Johnson, A. Quick, and M. Hastak, "Valuing the warranty ceiling clause on New Mexico Highway 44 using a binomial lattice model," Journal of Construction Engineering and Management, vol. 134, no. 1, pp. 10-17, 2008. 


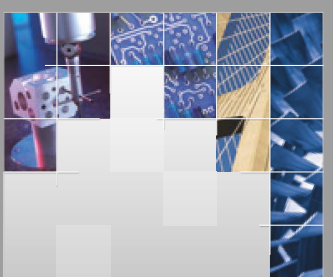

\section{Enfincering}
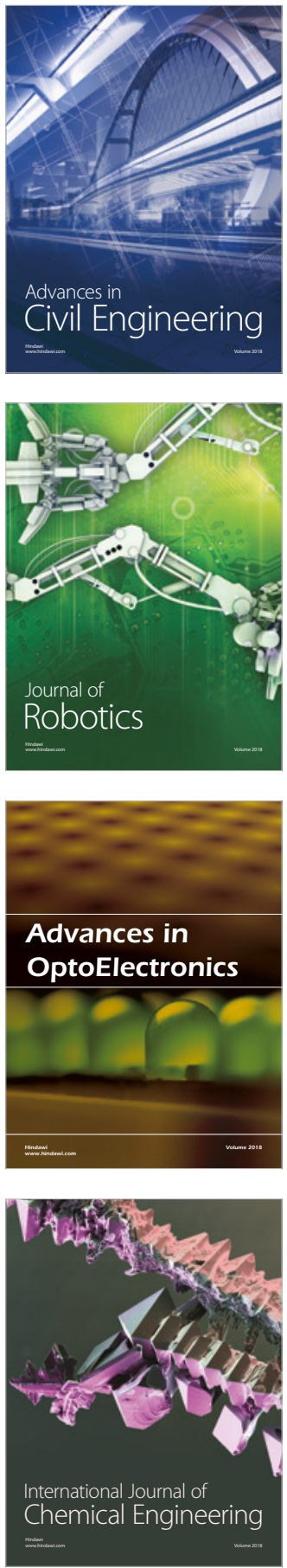

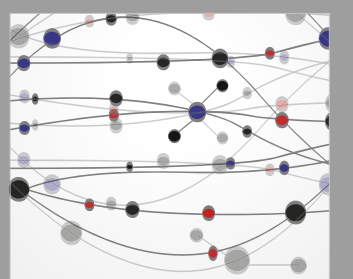

\section{Rotating \\ Machinery}

The Scientific World Journal

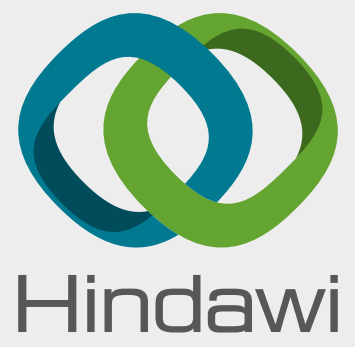

Submit your manuscripts at

www.hindawi.com
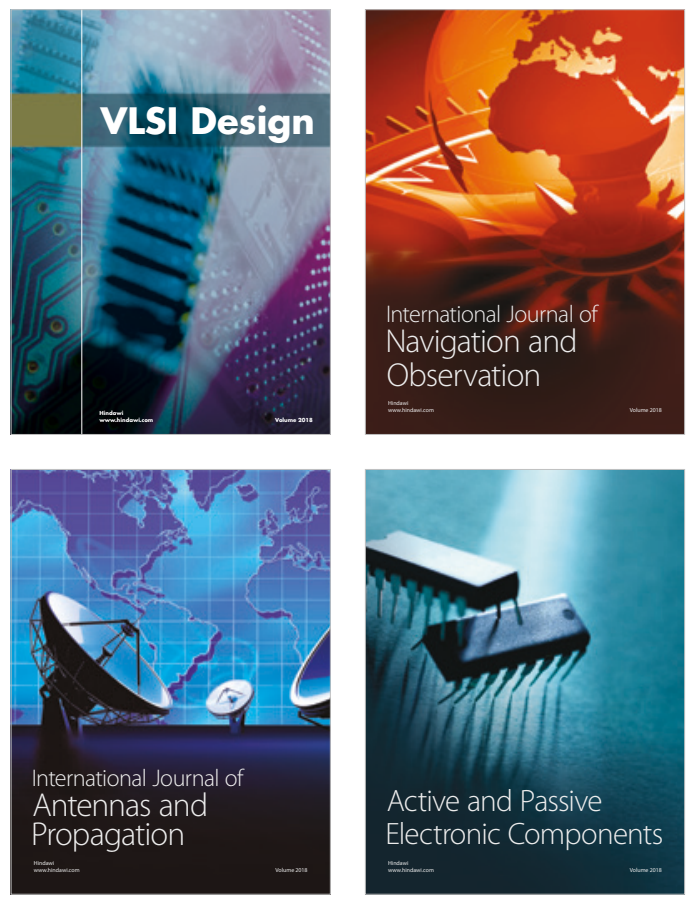
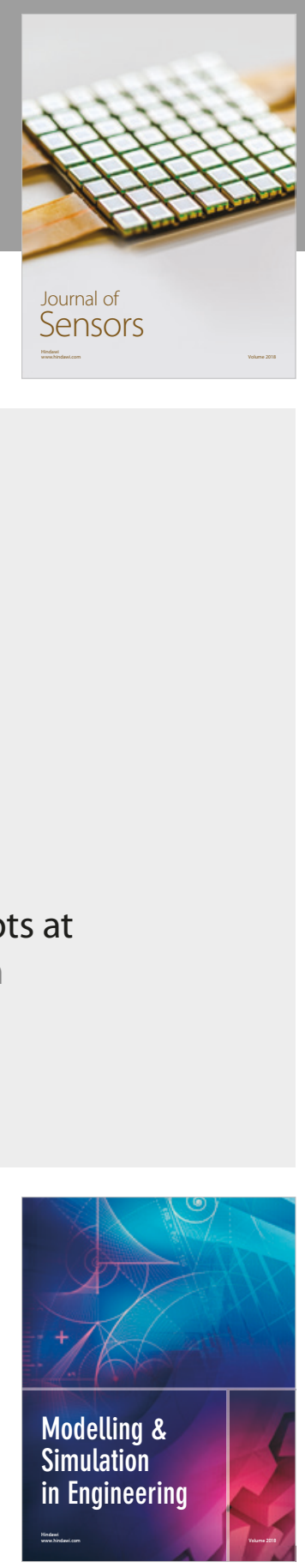

\section{Advances \\ Multimedia}
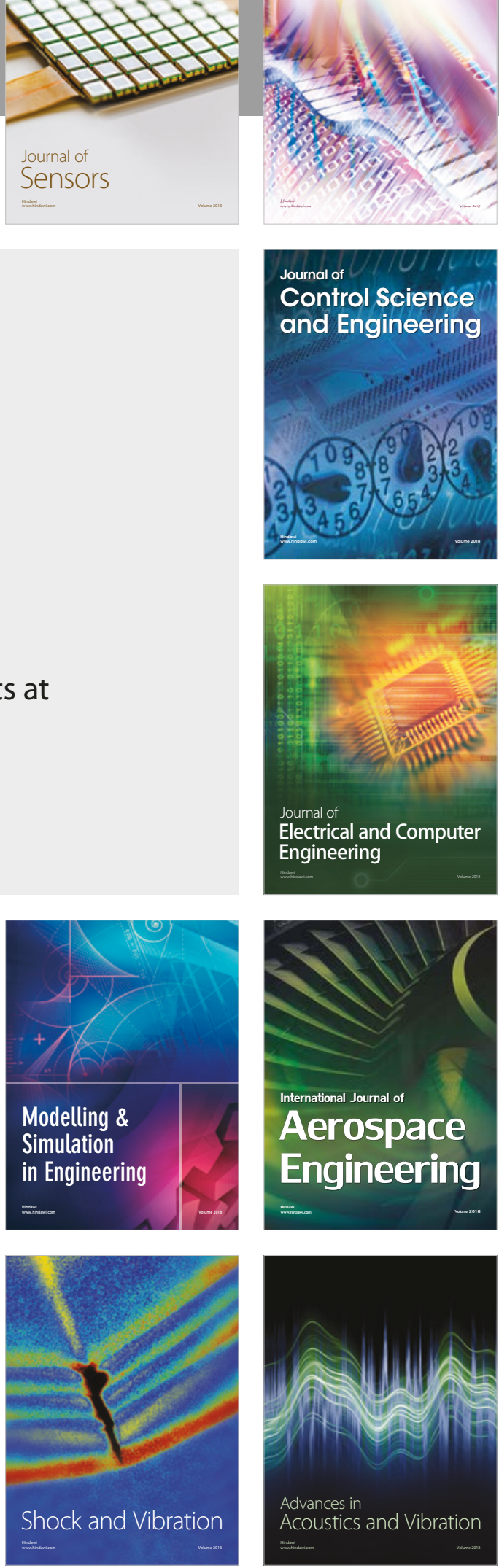